Article

\title{
Effects of Gestational Age and Early Parenting on Children's Social Inhibition at 6 Years
}

\author{
Lucia M. Reyes ${ }^{1}$ (D), Julia Jaekel ${ }^{1,2}$ and Dieter Wolke ${ }^{2, *(\mathbb{D}}$ \\ 1 Department of Child and Family Studies, The University of Tennessee, Knoxville, TN 37996, USA \\ 2 Department of Psychology, University of Warwick, Coventry CV47AL, UK \\ * Correspondence: d.wolke@warwick.ac.uk; Tel.: +44-24-76573217
}

Received: 1 May 2019; Accepted: 25 June 2019; Published: 28 June 2019

\begin{abstract}
Preterm birth ( $<37$ weeks' gestation) has been associated with problems in social functioning. Whether social inhibition is specifically related to preterm birth and whether early parenting may protect against social inhibition difficulties is unknown. To explore effects of gestational age and early parent-infant relationships on social inhibition, 1314 children born at 26-41 weeks gestational age were studied as part of the prospective Bavarian Longitudinal Study. Early parent-infant relationship quality was assessed postnatally with the parent-infant relationship index. Social inhibition was assessed at age 6 years using an experimental procedure, in which nonverbal and verbal responses were coded into social inhibition categories (disinhibited, normally responsive, inhibited). Multinomial logistic regressions indicated that children with lower gestational age showed more socially disinhibited (nonverbal: $\mathrm{OR}=1.27$ [95\% CI $=1.17-1.40]$, verbal: $\mathrm{OR}=1.23$ [95\% CI 1.13-1.35]) and inhibited (nonverbal: $\mathrm{OR}=1.21[95 \% \mathrm{CI}=1.11-1.32]$, verbal: $\mathrm{OR}=1.11[95 \% \mathrm{CI}=1.01-1.21]$ ) responses. Good early parent-infant relationships were associated with less verbal disinhibition (OR $=0.70$ [95\% CI $=0.52-0.93])$. Findings suggest that children with lower gestational age are at greater risk to be both socially inhibited and disinhibited. Early parenting affected risk of abnormal social responses. Supporting early parent-infant relationships may reduce preterm children's risk for social difficulties.
\end{abstract}

Keywords: temperament; shyness; disinhibition; preterm birth

\section{Introduction}

Temperamental characteristics predict later socioemotional and behavioral problems [1]. Infants' and toddlers' behavioral inhibition - the temperamental tendency to react to novel stimuli with wariness and avoidance [2] — for example, is a precursor to social reticence [3] and predictive of anxiety in middle childhood and adolescence [4-6]. Social inhibition, which specifically refers to responses to unfamiliar social stimuli, is more closely associated with later socially anxious behaviors than inhibition towards nonsocial stimuli [7,8]. In contrast to social disinterest, social inhibition reflects emotional dysregulation characterized by high fear in low-threat situations [9]. In young children (2-6 years), social inhibition is assessed via the quality and timing of responses to an adult stranger $[7,10,11]$. Efforts to identify an early-life at-risk phenotype for social anxiety have focused on neurobiological correlates of inhibited temperament and suggest that specific brain circuits underlie its behavioral manifestation [12]. However, the role of perinatal risk on the development of social inhibition is not well understood [13].

Preterm birth ( $<37$ weeks gestation) is known to cause brain injury and alterations [14] that may be related to the development of inhibited temperament [15], thus putting preterm children at risk for social difficulties [16]. Compared to their full-term (39-41 weeks) peers, very preterm $(<32$ weeks) children show more peer problems, greater social withdrawal, and poorer social skills [16-18], which may increase their risk of social exclusion and being bullied by peers [19]. These difficulties appear to 
be long-lasting, as extremely preterm ( $<28$ weeks gestation) individuals have more peer problems and lower confidence in adolescence [20], and more shyness and lower sociability in early adulthood [21,22]. Very preterm adults are also at greater risk for low social support $[23,24]$ and a withdrawn personality type $[25,26]$. Although early temperamental traits may underlie these difficulties, previous studies have not used experimental paradigms to assess preterm children's social inhibition.

Further, whereas very preterm children have a known greater risk of social problems than term-born peers, less is known about children born moderately (32-33 weeks gestation) and late preterm (34-36 weeks gestation; [27]). The scarce evidence suggests that they might also be at risk for socioemotional problems compared to full-term counterparts [28]. For instance, mothers of late preterm infants rate their children more highly on temperamental negativity than do mothers of full-term infants [27]. By school age, late preterm children have more internalizing and externalizing problems, lower IQ, more school problems [29,30], and fewer friends [31] than full-term peers. Thus, temperamental characteristics (i.e., social inhibition) might offer a potential pathway to the subsequent social difficulties observed in individuals born very preterm, but whether these effects gradually increase with neonatal risk across the full range of gestation remains unknown.

Although positive early parent-infant relationships are important for all children, their contribution may be especially protective for preterm children's social development. High-quality parent-child interactions have been positively associated with preterm children's early social-emotional competence [32-34], particularly for those with higher medical risk [35,36]. Children born with very low birth weight $(<1500 \mathrm{~g})$ are more vulnerable than normal birth weight children to the effects of parental depression [37] and insensitive parenting [38,39]. Less sensitive parenting predicts impairments in self-regulation in very preterm toddlers [40], while maternal anxiety and negative or intrusive parenting predict poorer social competence at age 4 years of age [17].

Therefore, using data from a larger longitudinal study, the current study aimed to investigate the impact of gestational age and parent-infant relationships on social inhibition across the full gestation range. The current research questions were developed after the data collection had been finalized in the larger study. It was hypothesized that lower gestational age would predict higher social inhibition, and that good early parent-infant relationships would predict lower social inhibition.

\section{Materials and method}

\subsection{Participants}

Participants were recruited as part of the larger prospective, geographically defined, whole population Bavarian Longitudinal Study of neonatal at-risk children in Germany. All infants born between January 1985 and March 1986 admitted to a children's hospital within the first 10 days of life ( $n=7505 ; 10.6 \%$ of all live births), and 916 healthy term control infants born in the same hospitals during the same period, who received normal postnatal care, were recruited into the study and assessed at birth and 5 months of age. At age 6 years, $n=1314$ of the initial sample, stratified by sex, socioeconomic status (SES), and degree of neonatal risk, were selected for follow up [38,41]. Ethical approval was granted by the Ethics Committee of the University of Munich Children's Hospital and the Bavarian Health Council (Landesärztekammer). Parents provided written informed consent to participate in the study within $48 \mathrm{~h}$ of their child's birth. Further details of the study design can be found elsewhere [38,41].

\subsection{Measures}

Biological and sociodemographic variables at birth. Gestational age, birth weight, and sex were obtained from obstetric records. Family SES at birth was based on maternal and paternal education and occupational status and coded from 1 (lowest) to 6 (highest social class) [42], then reverse coded for analyses. 
Parent-infant relationship. Early parent-infant relationship quality was assessed with the parent-child relationship index (PIRI) from birth to five months [43,44]. The instrument consists of eight yes/no items obtained from trained nurses' observations and a standardized interview with the infants' parents, assessing attachment-related parental concerns, feelings, and behaviors, with items such as: mother shows little pleasure when interacting with the child (nurse's observation, neonatal), and mother has difficulties in establishing a relationship to the infant (mother interview, at 5 months of age). After all items were obtained, the sum of responses was calculated and recoded into one binary variable $(0=$ no concerns, $1=$ some degree of concern). Further details of this assessment are described in Table S1 in the Supplementary Material section (see also [43]).

Social inhibition assessment. At age 6 years, children's social inhibition in an unfamiliar setting was assessed with a standardized experimental procedure of the child's interaction with an adult stranger [10]. The task was designed to specifically test children's temperamental social inhibition and had high inter-rater (93-94) and retest ( 0.75 between ages 4 and 6 years) reliability in the original study [10]. Children and their mothers were placed in a specially equipped soundproof room without toys. The mother was seated 1.5 to $2 \mathrm{~m}$ away from the child and instructed to answer a written questionnaire and not actively engage with the child. When the child started to show signs of being bored (between 2 to $5 \mathrm{~min}$ after entering the room), an adult stranger entered with a transparent bag filled with toys, greeted child and mother, and sat down opposite of the mother about $1 \mathrm{~m}$ from the child. The stranger then started unpacking the bag of toys and playing with them while looking at the child every ten seconds but not actively approaching the child. If the child had not initiated nonverbal (e.g., pointing to toy and looking at stranger) or verbal (e.g., asking for toy; saying hello) contact after $180 \mathrm{~s}$ had passed, the stranger asked if (s)he wanted to play with the toys. The number of seconds that passed before the child initiated verbal or nonverbal contact (either before or after the stranger's cue) was recorded with a stopwatch. Based on the distribution of responses for the healthy (i.e., not neonatally hospitalized) full-term children (Figures 1 and 2), latencies of all children's nonverbal and verbal responses to the stranger were coded into 3 social approach categories: $1=$ disinhibited (response nonverbal: $<180 \mathrm{~s}$; verbal: $<180 \mathrm{~s}$ ), 2 = normally responsive (response nonverbal: 180-188 s; verbal: $180-227 \mathrm{~s}$ ) and $3=$ inhibited (response nonverbal: $>188 \mathrm{~s}$, verbal $>227$ ). This response pattern corresponded with the experimental stimulus (i.e., the stranger inviting the child to play after $180 \mathrm{~s}$ ); thus, children were coded as not socially inhibited or disinhibited if they showed the expected developmentally-appropriate response to the social cue. Further details for the coding of this assessment are provided in Tables S2 and S3 in the Supplementary Material section. 

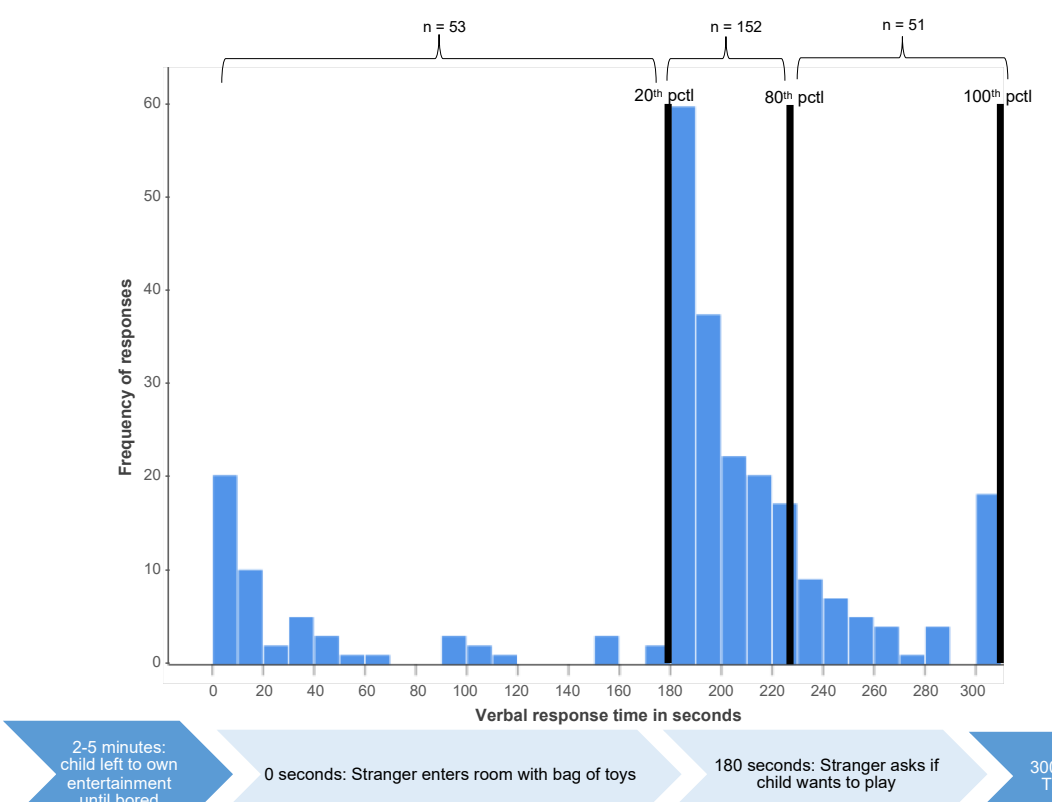

0 seconds: Stranger enters room with bag of toys

180 seconds: Stranger asks if

\section{0 seconds:
Task ends}

Figure 1. Distribution of healthy (i.e., non-neonatally hospitalized) full-term control children's ( $n=256)$ latencies of verbal response on social inhibition assessment. Note: Response time for children that showed no social reaction by $300 \mathrm{~s}$ (end of the task) was coded as $301 \mathrm{~s}$. Pctl = percentile.

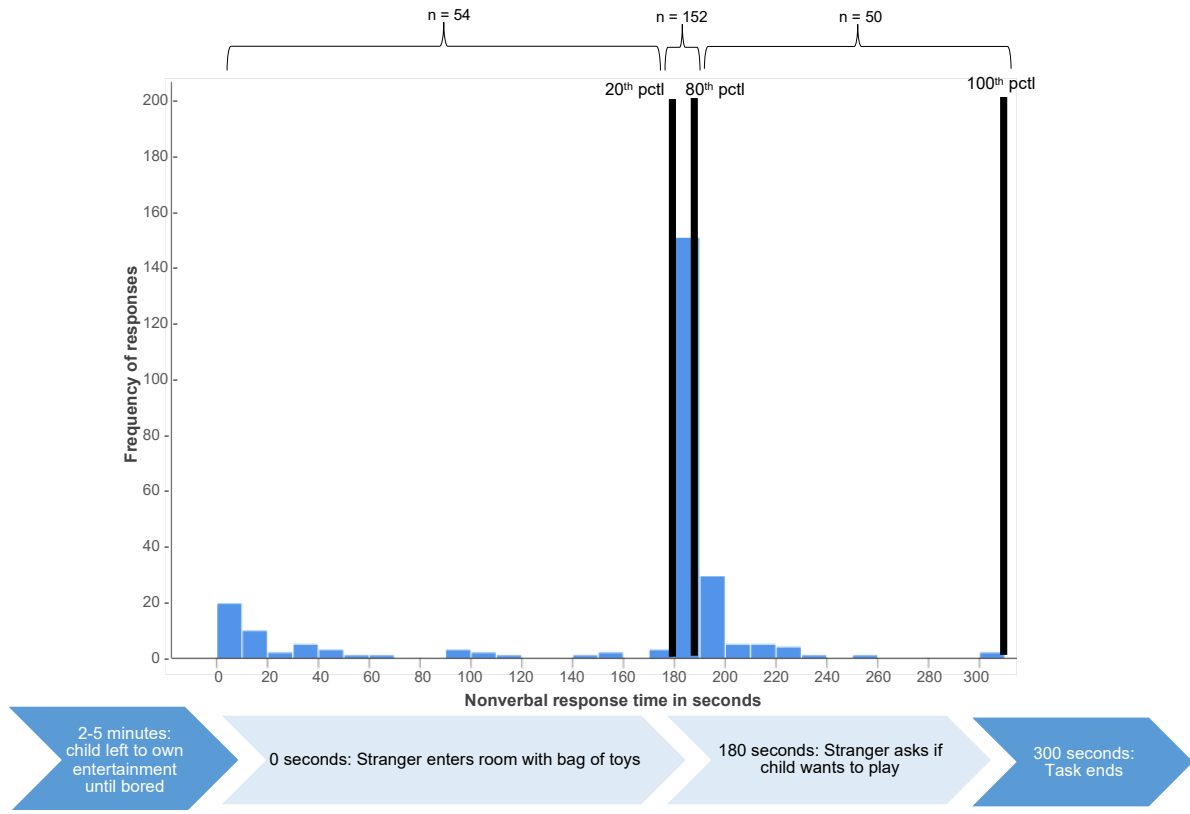

Figure 2. Distribution of healthy (i.e., non-neonatally hospitalized) full-term control children's $(n=256)$ latencies of nonverbal response on social inhibition assessment. Note: Response time for children that showed no social reaction by $300 \mathrm{~s}$ (end of the task) was coded as $301 \mathrm{~s}$. Pctl = percentile.

\subsection{Statistical Analysis}

All analyses were performed using SPSS v. 24 (Chicago, IL, USA). Mean values and frequencies for descriptive characteristics were calculated and are reported by gestational age group in Table 1 . Multinomial logistic regressions were performed to determine the impact of higher gestational age and PIRI scores on social inhibition behavior compared to the 'normal response' (nonverbal: 180-188 s; verbal: 180-227 s), controlling for sex and SES. Regressions were performed for both verbal and nonverbal responses with gestational age group (i.e., $1=$ full term, $2=$ early term, $3=$ late preterm, $4=$ moderately preterm, $5=$ very preterm) and PIRI (i.e., $0=$ no concern, $1=$ some concern) as 
predictors of interest. In addition to main effects, the interaction of gestational age group with PIRI scores was tested. Finally, multinomial regressions were used to calculate the relative odds of verbal inhibition and disinhibition for each gestational age group compared to the full-term group.

\section{Results}

Table 1 outlines descriptive characteristics of the final sample according to gestational age group status. Preliminary analyses showed no statistically significant differences in sex across groups, but lower gestational age was associated with lower SES and poorer PIRI scores. Frequencies of the social inhibition assessment results by gestational age groups are presented in Table 2. Children of lower gestation were not only more likely to show socially inhibited but also disinhibited verbal and nonverbal responses than those of higher gestational age groups.

Table 1. Descriptive background characteristics by gestational age groups $(n=1314)$.

\begin{tabular}{|c|c|c|c|c|c|c|}
\hline Background Characteristics & $\begin{array}{c}\text { Very } \\
\text { Preterm } \\
32 \mathrm{w} \text { GA } \\
n=229\end{array}$ & $\begin{array}{c}\text { Moderately } \\
\text { Preterm } \\
\text { 32-33 w GA } \\
n=90\end{array}$ & $\begin{array}{c}\text { Late } \\
\text { Preterm } \\
34-36 \text { w GA } \\
n=205\end{array}$ & $\begin{array}{c}\text { Early } \\
\text { Term } \\
\text { 37-38 w GA } \\
n=199\end{array}$ & $\begin{array}{c}\text { Full } \\
\text { Term } \\
\text { 39-41 w GA } \\
n=591\end{array}$ & $F / X^{2}(\mathrm{df}), p$ Value \\
\hline Gestational age in weeks M(SD) & $29.5(1.5)$ & $32.5(0.5)$ & $35.1(0.8)$ & $37.6(0.5)$ & $40.0(0.7)$ & $F(4,1309)=6687 \cdot 2^{* * *}$ \\
\hline Birth weight in grams $\mathrm{M}(\mathrm{SD})$ & $1,287(323)$ & $1,640(375)$ & $2,219(547)$ & $2,827(559)$ & $3,407(504)$ & $F(4,1309)=951.3^{* * *}$ \\
\hline Child sex (\% male) & $57.2 \%$ & $47.8 \%$ & $50.2 \%$ & $48.2 \%$ & $50.1 \%$ & $X^{2}(4,1314)=4.7$ \\
\hline SES $(1=$ high, $6=$ low $)$ M(SD) & $3.5(1.5)$ & $3.5(1.6)$ & $3.4(1.6)$ & $3.3(1.6)$ & $3.4(1.5)$ & $F(4,1309)=0.7$ \\
\hline Good parent-infant relationship & $50.7 \%$ & $58.9 \%$ & $62.9 \%$ & $66.3 \%$ & $70.1 \%$ & $X^{2}(4,1314)=28.7^{* * *}$ \\
\hline
\end{tabular}

Note. $w$ GA = weeks of gestation. SES = socioeconomic status. Data are presented as Mean (Standard Deviation) for interval scaled and percentages for categorical variables. ${ }^{* * *} p>0.001$.

Table 2. Raw frequencies of nonverbal and verbal inhibition by gestational age group $(n=1314)$.

\begin{tabular}{|c|c|c|c|c|c|c|}
\hline & $\begin{array}{c}\text { Very } \\
\text { Preterm } \\
32 \text { w GA } \\
n=229\end{array}$ & $\begin{array}{c}\text { Moderately } \\
\text { Preterm } \\
\text { 32-33 w GA } \\
n=90\end{array}$ & $\begin{array}{c}\text { Late } \\
\text { Preterm } \\
34-36 \text { w GA } \\
n=205\end{array}$ & $\begin{array}{c}\text { Early Term } \\
37-38 \text { w GA } \\
n=199\end{array}$ & $\begin{array}{c}\text { Full Term } \\
39-41 \text { w GA } \\
n=591\end{array}$ & $\begin{array}{c}X^{2}(\mathrm{df}), p \\
\text { Value }\end{array}$ \\
\hline \multicolumn{6}{|l|}{ Nonverbal Inhibition a } & \multirow{3}{*}{$41.26(8) * * *$} \\
\hline Disinhibited (\%) & $32.30 \%$ & $27.80 \%$ & $21.50 \%$ & $24.60 \%$ & $17.40 \%$ & \\
\hline Inhibited (\%) & $26.60 \%$ & $30.00 \%$ & $24.90 \%$ & $24.10 \%$ & $20.10 \%$ & \\
\hline \multicolumn{6}{|l|}{ Verbal Inhibition $^{b}$} & \multirow{3}{*}{$30.37(8) * * *$} \\
\hline Disinhibited (\%) & $31.40 \%$ & $26.70 \%$ & $21.00 \%$ & $23.10 \%$ & $17.10 \%$ & \\
\hline Normal response (\%) & $43.70 \%$ & $47.80 \%$ & $50.20 \%$ & $50.80 \%$ & $60.40 \%$ & \\
\hline
\end{tabular}

Note. $w G A=$ weeks of gestation. ${ }^{\text {a }}$ The following categorization was used for nonverbal responses: $<180 \mathrm{~s}=$ disinhibited; $180-188 \mathrm{~s}=$ normal; $>188 \mathrm{~s}=$ inhibited. $^{\mathrm{b}}$ The following categorization was used for verbal responses: $<180 \mathrm{~s}=$ disinhibited; $180-227 \mathrm{~s}=$ normal; $>227 \mathrm{~s}=$ inhibited. ${ }^{* * *} p>0.001$.

Results for multinomial logistic regressions are displayed in Tables 3 and 4. Children born with lower gestational age had higher odds of exhibiting socially inhibited (nonverbal: $\mathrm{OR}=1.21[95 \% \mathrm{CI}=$ 1.11-1.32], verbal: 1.11 [95\% CI $=1.01-1.21]$ ) response behavior. Thus, on average, each lower gestational age group had $21 \%$ increased odds of nonverbal inhibition and $11 \%$ increased odds of verbal inhibition than the next higher gestation group, controlling for sex, SES, and parent-infant relationship quality. Additionally, children of lower gestational age groups were more likely to show socially disinhibited responses (nonverbal: $\mathrm{OR}=1.27[95 \% \mathrm{CI}=1.17-1.40]$, verbal: $\mathrm{OR}=1.23$ [95\% CI $=1.13-1.35]$ ), meaning that on average, each lower gestational age group had $27 \%$ increased odds of nonverbal disinhibition and $23 \%$ increased odds of verbal disinhibition compared to the next gestational age group. 
Table 3. Multinomial logistic regression results for variables predicting nonverbal response $(n=1314)$.

\begin{tabular}{cccccccc}
\hline & Variable & $\boldsymbol{B}$ & SE $\boldsymbol{B}$ & Wald & df & OR & 95\% CI \\
\hline \multirow{4}{*}{ Disinhibited } & Intercept & $-0.86^{* * *}$ & 0.24 & 13.03 & 1 & & \\
$180 \mathrm{~s}$ & Sex (male) & 0.27 & 0.14 & 3.50 & 1 & 1.31 & $0.99-1.73$ \\
& Lower SES & $-0.18^{* * *}$ & 0.05 & 15.19 & 1 & 0.84 & $0.77-0.92$ \\
& Lower gestational age & $0.24^{* * *}$ & 0.05 & 27.77 & 1 & 1.27 & $1.17-1.40$ \\
& Good parenting & -0.27 & 0.15 & 3.33 & 1 & 0.77 & $0.57-1.02$ \\
\hline \multirow{2}{*}{ Inhibited } & Intercept & $-1.04^{* * *}$ & 0.24 & 18.55 & 1 & & \\
$>188 \mathrm{~s}$ & Sex (male) & $-0.36^{* *}$ & 0.14 & 6.79 & 1 & 0.70 & $0.53-0.91$ \\
& Lower SES & -0.02 & 0.05 & 0.27 & 1 & 0.98 & $0.90-1.07$ \\
& Lower gestational age & $0.19^{* * *}$ & 0.05 & 17.09 & 1 & 1.21 & $1.11-1.32$ \\
& Good parenting & 0.01 & 0.15 & 0.00 & 1 & 1.01 & $0.76-1.35$ \\
\hline & $L R \chi^{2}$ & $70.09^{* * *}$ & & & & &
\end{tabular}

Note: ${ }^{* *} p<0.01,{ }^{* * *} p<0.001$. The reference category is "normal" (180-188 s) nonverbal response.

Table 4. Multinomial logistic regression results for variables predicting verbal response $(n=1314)$.

\begin{tabular}{cccccccc}
\hline & Variable & $\boldsymbol{B}$ & SE $\boldsymbol{B}$ & Wald & df & OR & 95\% CI \\
\hline \multirow{4}{*}{ Disinhibited } & Intercept & $-0.99^{* * *}$ & 0.24 & 16.91 & 1 & & \\
180 s & Sex (male) & $0.40^{* *}$ & 0.05 & 7.80 & 1 & 1.50 & $1.13-1.98$ \\
& Lower SES & $-0.13^{* *}$ & 0.05 & 7.80 & 1 & 0.88 & $0.81-0.96$ \\
& Lower gestational age & $0.21^{* * *}$ & 0.05 & 20.75 & 1 & 1.23 & $1.13-1.35$ \\
& Good parenting & $-0.36^{*}$ & 0.15 & 6.02 & 1 & 0.70 & $0.52-0.93$ \\
\hline \multirow{2}{*}{ Inhibited } & Intercept & $-1.45^{* * *}$ & 0.25 & 34.76 & 1 & & \\
$>227 \mathrm{~s}$ & Sex (male) & 0.01 & 0.14 & 0.00 & 1 & 1.01 & $0.77-1.31$ \\
& Lower SES & $0.16^{* *}$ & 0.05 & 11.68 & 1 & 1.17 & $1.07-1.28$ \\
& Lower gestational age & $0.10^{*}$ & 0.05 & 4.99 & 1 & 1.11 & $1.01-1.21$ \\
& Good parenting & -0.19 & 0.14 & 1.73 & 1 & 0.83 & $0.63-1.10$ \\
\hline & $L R \chi^{2}$ & $68.87^{* * *}$ & & & & & \\
\hline
\end{tabular}

Note: ${ }^{*} p<0.05,{ }^{* *} p<0.01,{ }^{* * *} p<0.001$. The reference category is "normal" (180-227 s) verbal response.

Good early parent-infant relationship quality was not associated with differences in verbal nor nonverbal inhibition, but with lower verbal disinhibition ( $\mathrm{OR}=0.70[95 \% \mathrm{CI}=0.52-0.93]$ ), after controlling for child sex, family SES, and gestational age group. In other words, children with a good PIRI score had 30\% decreased odds of having verbally disinhibited responses. Because there was not a significant interaction effect of parent-infant relationship with gestational age on social inhibition, results reported above are only for the more parsimonious models without the nonsignificant interaction term. Results for the models with the interaction term can be found in Tables S4 and S5 in the Supplementary Material. Frequencies of the social inhibition assessment verbal results by PIRI score are presented in Table 5.

Table 5. Raw frequencies of verbal inhibition by gestational age group and parent-infant relationship index (PIRI).

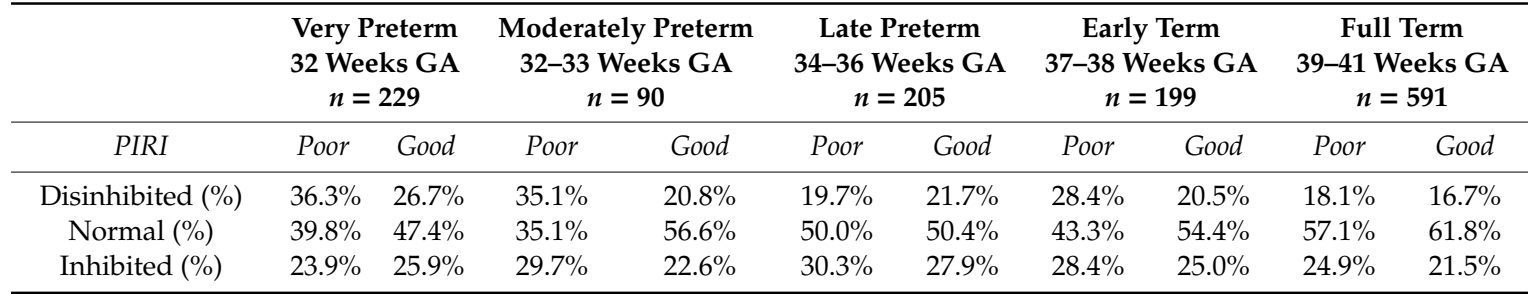

Note. $w G A=$ weeks of gestation. PIRI = parent-infant relationship index. The following categorization was used for verbal inhibition responses: $<180 \mathrm{~s}=$ disinhibited; $180-227 \mathrm{~s}=$ normal; $>227 \mathrm{~s}=$ inhibited. 
Results of multinomial regressions comparing verbal responses for each gestational age group to the full-term group are shown in Table 6, and odds ratios are presented in Figure 3 for social inhibition and Figure 4 for disinhibition.

Table 6. Multinomial logistic regression results for gestational age group predicting verbal response compared to the full-term group.

\begin{tabular}{cccccccc}
\hline & Variable & $\boldsymbol{B}$ & SE $\boldsymbol{B}$ & Wald & df & OR & 95\% CI \\
\hline \multirow{4}{*}{ Disinhibited } & Intercept & -1.09 & 0.20 & 29.39 & 1 & & \\
& Sex (male) & $0.40^{* *}$ & 0.14 & 7.78 & 1 & 1.49 & $1.13-1.98$ \\
& Lower SES & $-0.12^{* *}$ & 0.05 & 6.93 & 1 & 0.89 & $0.81-0.97$ \\
& Very preterm & $0.93^{* * *}$ & 0.19 & 23.31 & 1 & 2.54 & $1.74-3.70$ \\
& Moderately preterm & $0.71^{*}$ & 0.28 & 6.37 & 1 & 2.03 & $1.17-3.52$ \\
& Late preterm & 0.38 & 0.22 & 3.08 & 1 & 1.46 & $0.96-2.22$ \\
& Early term & $0.48^{*}$ & 0.21 & 5.04 & 1 & 1.61 & $1.06-2.44$ \\
\hline \multirow{3}{*}{ Inhibited } & Intercept & $-1.57^{* * *}$ & 0.21 & 58.24 & 1 & & \\
& Sex (male) & 0.01 & 0.14 & 0.00 & 1 & 1.01 & $0.77-1.32$ \\
& Lower SES & $0.16^{* * *}$ & 0.05 & 12.87 & 1 & 1.18 & $1.08-1.29$ \\
& Very preterm & $0.41^{*}$ & 0.20 & 4.32 & 1 & 1.50 & $1.02-2.20$ \\
& Moderately preterm & 0.34 & 0.28 & 1.47 & 1 & 1.40 & $0.81-2.42$ \\
& Late preterm & $0.44^{*}$ & 0.19 & 5.27 & 1 & 1.56 & $1.07-2.28$ \\
& Early term & 0.34 & 0.20 & 2.82 & 1 & 1.40 & $0.95-2.07$ \\
\hline & $L R \chi^{2}$ & $67.02 * * *$ & & & &
\end{tabular}

Note: ${ }^{*} p<0.05,{ }^{* *} p<0.01,{ }^{* * *} p<0.001$. The reference category is "normal" (180-227 s) verbal response. $n=1314$.

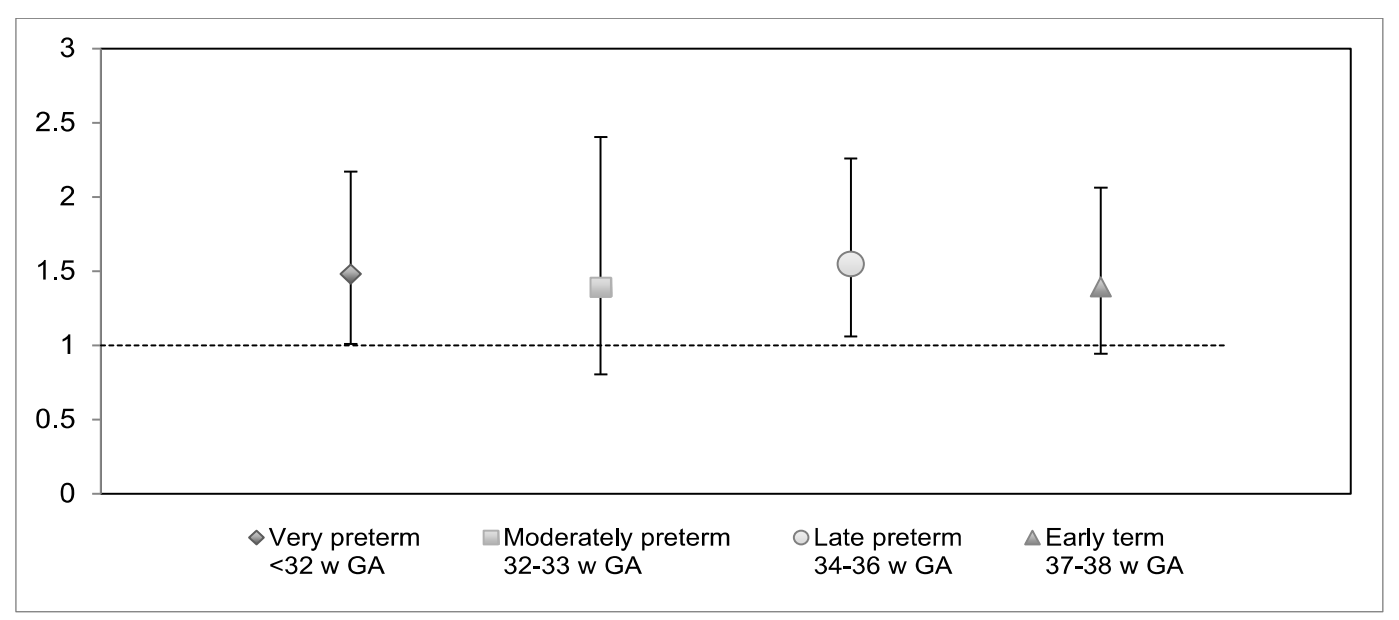

Figure 3. Odds ratios (OR) for verbal inhibition by gestational age group compared to the full-term group, controlled for sex and socioeconomic status. Note. $w$ GA = weeks of gestation. Error bars denote 95\% confidence intervals. There was a significant effect of lower socioeconomic status (OR: 1.18 [95\% CI: 1.08-1.29]) on increased verbal inhibition. 


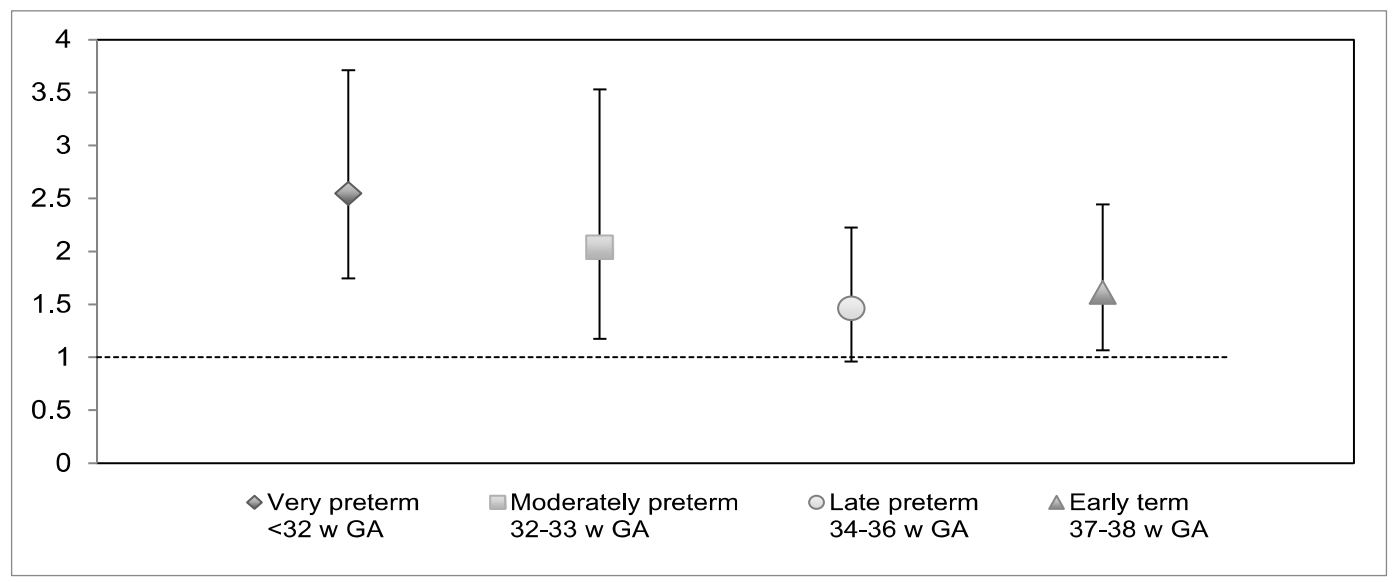

Figure 4. Odds ratios (OR) for verbal disinhibition by gestational age group compared to the full-term group, controlled for sex and socioeconomic status. Note. $w$ GA = weeks of gestation. Error bars denote 95\% confidence intervals. There was a positive effect of male sex (OR: 1.49 [95\% CI $=1.13-1.98]$ ) and a negative effect of lower socioeconomic status (OR: 0.89 [95\% CI $=0.81-0.97]$ ) on increased disinhibition.

\section{Discussion}

This study investigated effects of early parent-infant relationship quality and preterm birth across the whole gestational age range on children's social inhibition at 6 years. It was found that children with lower gestational age had higher odds of being socially inhibited and disinhibited than children with higher gestational age. In addition, good parent-infant relationship quality was associated with less verbal disinhibition.

These findings add to the existing literature suggesting that both gestational age [15] and early parenting [45] impact children's approach in unfamiliar social situations. New is that this study identified that both ends of temperamental approach tendencies may underlie social difficulties in preterm children; being either inhibited (withdrawn) or disinhibited may put preterm children at higher risk of social rejection in relationships. Further, this study adds to existing literature on the importance of early parenting in protecting against difficulties for children across the whole gestational age range [33]. Studies have documented that social problems in very preterm individuals prevail into adolescence and adulthood $[20,26,46]$, and results of the current study illuminate a potential underlying temperamental pathway, evident in early childhood. Previous work has also suggested that prematurity might impact the development of temperament [47], and the current study identifies social inhibition as a more precise temperamental trait with extremes of inhibition and disinhibition that are more prevalent with lower gestation at birth and might help to explain the persistence and trajectory of social problems. Temperament-based inhibition towards unfamiliar social stimuli can be distinguished from inhibition due to social-evaluative concerns (see [10]). Our study explored the former and suggests that prematurity is related to inhibition towards unfamiliarity. Interestingly, these findings do not only point to increased social inhibition but also disinhibition as a potential precursor of later social behavior problems following preterm birth. Both deviations from normal approach behavior may put preterm children at risk for adverse social interactions such as bullying [19,48], adding to social difficulties preterm children may have. Additionally, the current findings extend the emerging literature on social problems among moderate and late preterm individuals $[27,29,49]$, underscoring the importance of considering degree of prematurity [50].

To our knowledge, this is the first investigation of the potential neurodevelopmental mechanisms underlying children's social difficulties across the full range of gestation. The findings are suggestive of a dose-response effect of low gestational age on the ability to inhibit and disinhibit behavioral responses to new social situations. One potential mechanism for this social dysregulation among preterm children may involve structural and functional brain alterations [51,52]. A strong body of literature has demonstrated the role of brain connectivity in supporting emotional signaling and affect 
sharing [53-56], which are foundational to social engagement [57] and, more generally, to what is known as the "social brain" - the network of brain areas involved in recognition and evaluation of others and their mental states [58]. Preterm children are at risk for brain injury and neuronal/axonal disease [14], which may alter the structure and subsequent typical maturation of certain brain regions [59], including those involved in processing faces, detecting and responding to social cues, evaluating emotion, and processing others' actions (for a review, see [51]).

During the first months of life, preterm infants have greater difficulty orienting to social stimuli and maintaining social interactions [60,61] and positive affect when attending to faces [62-64]. A recent study showed that infants born preterm ( $>35$ weeks) with compromised brainstem functions during the perinatal period were at greater risk to display difficulties in regulating gaze during face-to-face interactions at 4 months than healthy preterm infants [13], suggesting that humans may be programmed for social interactions before experiencing social encounters. Further supporting this hypothesis, a subsequent study of this sample found that the risk of compromised brainstem functions involved in behavioral inhibition at 12 months was moderated by gaze engagement at 4 months [15]. While only a few studies have investigated associations of structural brain alterations with socioemotional outcomes in preterm individuals $[52,65,66]$, the current evidence in this area also supports a neurodevelopmental pathway to social difficulties [51].

On the other hand, the etiology of disinhibited social behavior remains less clear. In the temperament literature, an abnormally high approach to novel social stimuli, including strangers, has been referred to as exuberance $[67,68]$, or behavioral disinhibition [69], although it is acknowledged that the construct involves aspects previously regarded as high approach [70], high novelty seeking, and low harm avoidance [71]. However, preterm children and adults have been consistently found to show low novelty seeking [52,72,73], suggesting that the avenue to social disinhibition may be either related to altered brain development or early adverse experiences [74] and hospitalization or both. Most of these perspectives, nonetheless, recognize the role of the behavioral activation system (BAS), or motivation in disinhibition, and it is suggested that problems in inhibitory control might underlie social disinhibition $[69,75]$. Preterm children have been consistently shown to have problems in self-control abilities and inhibiting unwanted responses [40,76], including poorer control of regulation of behavioral states [77]. Poor self-control may manifest as difficulty delaying approach to a stranger when motivated by a stimulus (i.e., toys in the current study), despite social appropriateness or safety. Future studies should include BAS and inhibitory control measures to explore potential moderators of disinhibited social behavior in preterm children, given that highly disinhibited behavior is also linked with later emotional and behavioral problems [78].

Another possibility is that the social disinhibition observed here may share etiological pathways with attachment formation, as is conceptualized with indiscriminate approach behavior in disinhibited social engagement disorder (DSED). While preterm children, in general, are not more often insecurely attached than their term-born peers, they do have higher rates of disorganized attachment [79]. However, preterm children's mothers are as sensitive as full-term children's mothers [80]. Differences in preterm children's attachment patterns could be partly attributable to the NICU experience, in which long hospitalization and incubator care limit contact with parents (e.g., touch, eye contact) and may hinder parent-child relationships [81-83]. Moreover, multiple painful procedures administered in the NICU may program the hypothalamic-pituitary-adrenal (HPA) axis for heightened reactivity [84]. Studies have not only shown that preterm infants are more likely to show dysregulated early behavior, such as crying, sleeping, and feeding problems [77] despite high-quality parenting [80], but that these early regulatory problems in preterm infants are more predictive of disorganized attachment than sensitive parenting [79]. Thus, early environmental factors beyond parenting (e.g., NICU, pain) as well as within child factors (e.g., brain injury, impaired neurodevelopment) and early regulatory problems should be considered as potential contributions to disinhibition.

Importantly, results of the current study indicate a protective effect of good parent-infant relationships against social dysregulation. In contrast to our expectations, there was not a significant 
interaction of gestational age and parent-infant relationship quality on social inhibition. It should be noted that interactions are often difficult to detect due to lack of statistical power; in this study, a nonsignificant trend showed greater importance of parent-infant relationship quality for very preterm and moderately preterm children's outcomes (Table 5). Overall, a good parent-infant relationship is protective for all infants, including those with high neonatal risk, from showing disinhibited verbal social behavior. There is a good case to assess the effectiveness of parent-infant interventions that have shown promise for preterm infant self-regulation [85].

Strengths of this study include its large, prospective, whole-population design, followed longitudinally until age 6 years, and its inclusion of control variables. In contrast to studies that rely on parent or teacher reports to assess children's temperamental traits [47,86-88], a standardized experimental observation measure of social inhibition was used [10]. To assess the quality of parent-child relationships, trained nurses' observations and parents' reports were combined into one score (i.e., the PIRI). Despite its ecological validity, limitations of the PIRI include its lack of inter-rater reliability information and the potential subjectivity of parent self-reports. Additional limitations of the study include sample recruitment between 1985 and 1986, which warrants replication with more recent samples. Nevertheless, comparisons of older with more recently born cohorts' long-term developmental outcomes suggest that, despite improved survival, neurodevelopmental outcomes have shown no change for the better over the last decades [41,89-92]. Since the first assessment of social inhibition in this study was conducted at six years, it was not possible to identify continuity in temperament from birth to age six, although temperamental traits are regarded as fairly stable across development [93]. Future studies could consider coding additional indicators of temperamental approach tendencies (e.g., emotional expressions), in addition to social response time during experimental tasks of children's interaction with adult strangers.

\section{Conclusions}

Results of this study add to emerging evidence of a dose-response effect of low gestation on children's social inhibition. Health care professionals can provide regular follow-up assessments of children born preterm to support screening and early identification of potential social competence problems [94]. Future interventions to improve social interaction skills should start before school entry to prevent long-term problems [95] and should emphasize the role of parents in promoting the social development of their children, especially for those born very and moderately preterm. Additionally, future studies that explore social inhibition as a developmental pathway to preterm individuals' later psychopathology [96] and social problems [97] constitute an important direction to shed light on the mechanisms explaining preterm individuals' long-term outcomes.

Supplementary Materials: The following are available online at http://www.mdpi.com/2227-9067/6/7/81/s1, Table S1: Parent-infant relationship index, Table S2: Social inhibition assessment, Table S3: Distribution of healthy full-term control group $(n=256)$ response to stranger in social inhibition assessment, Table S4: Multinomial logistic regression results for variables predicting nonverbal response including interaction term $(n=1314)$, Table S5: Multinomial logistic regression results for variables predicting verbal response, including interaction term $(n=1314)$.

Author Contributions: Conceptualization, L.M.R., J.J., and D.W.; methodology, L.M.R., J.J., and D.W.; validation, J.J. and D.W.; formal analysis, L.M.R. and J.J.; investigation, D.W.; resources, D.W.; data curation, L.M.R., J.J., and D.W.; writing-original draft preparation, L.M.R.; writing-review and editing, J.J. and D.W.; visualization, L.M.R and J.J.; supervision, J.J. and D.W.; project administration, D.W.; funding acquisition, D.W.

Funding: This research was funded by the German Federal Ministry of Education and Science (BMBF), grant numbers PKE24, JUG14, 01EP9504 and 01ER0801. The APC was funded by The University of Tennessee's Office of Research and Engagement and University Libraries via the Open Publishing Support Fund (OPSF).

Acknowledgments: We thank all Bavarian Longitudinal Study group members, pediatricians, psychologists, and research nurses and those who contributed to study organization, recruitment, and data collection. We especially thank the study participants and their families. 
Conflicts of Interest: The authors declare no conflict of interest. The funders had no role in the design of the study; in the collection, analyses, or interpretation of data; in the writing of the manuscript, or in the decision to publish the results.

\section{References}

1. Chronis-Tuscano, A.; Degnan, K.A.; Pine, D.S.; Perez-Edgar, K.; Henderson, H.A.; Diaz, Y.; Raggi, V.L.; Fox, N.A. Stable early maternal report of behavioral inhibition predicts lifetime social anxiety disorder in adolescence. J. Am. Acad. Child Adoles. Psychiatry 2009, 48, 928-935. [CrossRef] [PubMed]

2. Kagan, J.; Reznick, J.S.; Clarke, C.; Snidman, N.; Garcia-Coll, C. Behavioral inhibition to the unfamiliar. Child Dev. 1984, 55, 2212-2225. [CrossRef]

3. Fox, N.A.; Henderson, H.A.; Rubin, K.H.; Calkins, S.D.; Schmidt, L.A. Continuity and discontinuity of behavioral inhibition and exuberance: Psychophysiological and behavioral influences across the first four years of life. Child Dev. 2001, 72, 1-21. [CrossRef] [PubMed]

4. Hirshfeld, D.R.; Rosenbaum, J.F.; Biederman, J.; Bolduc, E.A.; Faraone, S.V.; Snidman, N.; Reznick, J.S.; Kagan, J. Stable behavioral inhibition and its association with anxiety disorder. J. Am. Acad. Child Adoles. Psychiatry 1992, 31, 103-111. [CrossRef] [PubMed]

5. Biederman, J.; Hirshfeld-Becker, D.R.; Rosenbaum, J.F.; Hérot, C.; Friedman, D.; Snidman, N.; Kagan, J.; Faraone, S.V. Further evidence of association between behavioral inhibition and social anxiety in children. Am. J. Psychiatry 2001, 158, 1673-1679. [CrossRef]

6. Essex, M.J.; Klein, M.H.; Slattery, M.J.; Goldsmith, H.H.; Kalin, N.H. Early risk factors and developmental pathways to chronic high inhibition and social anxiety disorder in adolescence. Am. J. Psychiatry 2009, 167, 40-46. [CrossRef] [PubMed]

7. Dyson, M.; Klein, D.; Olino, T.; Dougherty, L.; Durbin, C. Social and non-social behavioral inhibition in preschool-age children: Differential associations with parent-reports of temperament and anxiety. Child Psychiatry Hum. Dev. 2011, 42, 390-405. [CrossRef]

8. Brooker, R.J.; Kiel, E.J.; Buss, K.A. Early social fear predicts kindergarteners' socially anxious behaviors: Direct associations, moderation by inhibitory control, and differences from nonsocial fear. Emotion 2016, 16, 997-1010. [CrossRef]

9. Buss, K.A.; Davis, E.L.; Ram, N.; Coccia, M. Dysregulated fear, social inhibition, and respiratory sinus arrhythmia: A replication and extension. Child Dev. 2018, 89, e214-e228. [CrossRef]

10. Asendorpf, J.B. Development of inhibition during childhood: Evidence for situational specificity and a two-factor model. Dev. Psychol. 1990, 26, 721-730. [CrossRef]

11. Andersson, K.; Bohlin, G.; Hagekull, B. Early temperament and stranger wariness as predictors of social inhibition in 2-year-olds. Br. J. Dev. Psychol. 1999, 17, 421-434. [CrossRef]

12. Fox, A.S.; Kalin, N.H. A translational neuroscience approach to understanding the development of social anxiety disorder and its pathophysiology. Am. J. Psychiatry 2014, 171, 1162-1173. [CrossRef] [PubMed]

13. Geva, R.; Sopher, K.; Kurtzman, L.; Galili, G.; Feldman, R.; Kuint, J. Neonatal brainstem dysfunction risks infant social engagement. Soc. Cogn. Affect. Neurosci. 2013, 8, 158-164. [CrossRef] [PubMed]

14. Volpe, J.J. Brain injury in premature infants: A complex amalgam of destructive and developmental disturbances. Lancet Neurol. 2009, 8, 110-124. [CrossRef]

15. Geva, R.; Schreiber, J.; Segal-Caspi, L.; Markus-Shiffman, M. Neonatal brainstem dysfunction after preterm birth predicts behavioral inhibition. J. Child Psychol. Psychiatry 2014, 55, 802-810. [CrossRef] [PubMed]

16. Ritchie, K.; Bora, S.; Woodward, L.J. Social development of children born very preterm: A systematic review. Dev. Med. Child Neurol. 2015, 57, 899-918. [CrossRef] [PubMed]

17. Jones, K.M.; Champion, P.R.; Woodward, L.J. Social competence of preschool children born very preterm. Early Hum. Dev. 2013, 89, 795-802. [CrossRef] [PubMed]

18. Delobel-Ayoub, M.; Kaminski, M.; Marret, S.; Burguet, A.; Marchand, L.; N'Guyen, S.; Matis, J.; Thiriez, G.; Fresson, J.; Arnaud, C.; et al. Behavioral outcome at 3 years of age in very preterm infants: The EPIPAGE Study. Pediatrics 2006, 117, 1996. [CrossRef]

19. Wolke, D.; Baumann, N.; Strauss, V.; Johnson, S.; Marlow, N. Bullying of preterm children and emotional problems at school age: Cross-culturally invariant effects. J. Pediatr. 2015, 166, 1417-1422. [CrossRef] 
20. Gardner, F.; Johnson, A.; Yudkin, P.; Bowler, U.; Hockley, C.; Mutch, L.; Wariyar, U. Behavioral and emotional adjustment of teenagers in mainstream school who were born before 29 weeks' gestation. Pediatrics 2004, 114, 676-682. [CrossRef]

21. Schmidt, L.A.; Miskovic, V.; Boyle, M.H.; Saigal, S. Shyness and timidity in young adults who were born at extremely low birth weight. Pediatrics 2008, 122, e181-e187. [CrossRef] [PubMed]

22. Pyhälä, R.; Räikkönen, K.; Pesonen, A.-K.; Heinonen, K.; Hovi, P.; Eriksson, J.G.; Järvenpää, A.-L.; Andersson, S.; Kajantie, E. Behavioral inhibition and behavioral approach in young adults with very low birth weight-The Helsinki study of very low birth weight adults. Personal. Individ. Differ. 2009, 46, 106-110. [CrossRef]

23. Darlow, B.A.; Horwood, L.J.; Pere-Bracken, H.M.; Woodward, L.J. Psychosocial outcomes of young adults born very low birth weight. Pediatrics 2013, 132, e1521-e1528. [CrossRef] [PubMed]

24. Jaekel, J.; Baumann, N.; Bartmann, P.; Wolke, D. Mood and anxiety disorders in very preterm/very low birth weight individuals from six to 26 years. J. Child Psychol. Psychiatry 2018, 59, 88-95. [CrossRef] [PubMed]

25. Eryigit Madzwamuse, S.; Baumann, N.; Jaekel, J.; Bartmann, P.; Wolke, D. Neuro-cognitive performance of very preterm or very low birth weight adults at 26 years. J. Child Psychol. Psychiatry 2015, 56, 857-864. [CrossRef] [PubMed]

26. Saigal, S.; Day, K.L.; Van Lieshout, R.J.; Schmidt, L.A.; Morrison, K.M.; Boyle, M.H. Health, wealth, social integration, and sexuality of extremely low-birth-weight prematurely born adults in the fourth decade of life. JAMA Pediatr. 2016, 170, 678-686. [CrossRef]

27. Voegtline, K.M.; Stifter, C.A.; Family Life Project, I. Late-Preterm Birth, Maternal symptomatology, and infant negativity. Infant Behav. Dev. 2010, 33, 545-554. [CrossRef] [PubMed]

28. De Jong, M.; Verhoeven, M.; van Baar, A.L. School Outcome, Cognitive Functioning, and Behaviour Problems in Moderate and Late Preterm Children and Adults: A Review. Semin. Fetal Neonatal Med. 2012, 17, 163-169. [CrossRef]

29. Talge, N.M.; Holzman, C.; Wang, J.; Lucia, V.; Gardiner, J.; Breslau, N. Late-preterm birth and its association with cognitive and socioemotional outcomes at 6 years of age. Pediatrics 2010, 126, 1124-1131. [CrossRef]

30. Van Baar, A.L.; Vermaas, J.; Knots, E.; de Kleine, M.J.K.; Soons, P. Functioning at school age of moderately preterm children born at 32 to 36 weeks' gestational age. Pediatrics 2009, 124, 251-257. [CrossRef]

31. Heuser, K.M.; Jaekel, J.; Wolke, D. Origins and predictors of friendships in 6- to 8-year-old children born at neonatal risk. J. Pediatr. 2018, 193, 93-101.e5. [CrossRef] [PubMed]

32. Landry, S.H.; Chapieski, M.L.; Richardson, M.A.; Palmer, J.; Hall, S. The social competence of children born prematurely: Effects of medical complications and parent behaviors. Child Dev. 1990, 61, 1605-1616. [CrossRef] [PubMed]

33. Treyvaud, K.; Anderson, V.A.; Howard, K.; Bear, M.; Hunt, R.W.; Doyle, L.W.; Inder, T.E.; Woodward, L.; Anderson, P.J. Parenting behavior is associated with the early neurobehavioral development of very preterm children. Pediatrics 2009, 123, 555-561. [CrossRef] [PubMed]

34. Poehlmann-Tynan, J.; Gerstein, E.D.; Burnson, C.; Weymouth, L.; Bolt, D.M.; Maleck, S.; Schwichtenberg, A.J. Risk and resilience in preterm children at age 6. Dev. Psychopath. 2014, 27, 843-858. [CrossRef] [PubMed]

35. Landry, S.H.; Smith, K.E.; Miller-Loncar, C.L.; Swank, P.R. Predicting cognitive-language and social growth curves from early maternal behaviors in children at varying degrees of biological risk. Dev. Psychol. 1997, 33, 1040-1053. [CrossRef] [PubMed]

36. Forcada-Guex, M.; Pierrehumbert, B.; Borghini, A.; Moessinger, A.; Muller-Nix, C. Early dyadic patterns of mother-infant interactions and outcomes of prematurity at 18 months. Pediatrics 2006, 118, e107-e114. [CrossRef] [PubMed]

37. Nomura, Y.; Wickramaratne, P.J.; Pilowsky, D.J.; Newcorn, J.H.; Bruder, B.; Davey, C.; Fifer, W.P.; Brooks-Gunn, J.; Weissman, M.M. Low birthweight and risk of affective disorders \& selected medical illness in offspring at high and low risk for depression. Compr. Psychiatry 2007, 48, 470-478. [CrossRef]

38. Jaekel, J.; Pluess, M.; Belsky, J.; Wolke, D. Effects of maternal sensitivity on low birth weight children's academic achievement: A test of differential susceptibility versus diathesis stress. J. Child Psychol. Psychiatry 2015, 56, 693-701. [CrossRef]

39. Wolke, D.; Jaekel, J.; Hall, J.; Baumann, N. Effects of sensitive parenting on the academic resilience of very preterm and very low birth weight adolescents. J. Adolesc. Health 2013, 53, 642-647. [CrossRef] 
40. Clark, C.A.C.; Woodward, L.J.; Horwood, L.J.; Moor, S. Development of emotional and behavioral regulation in children born extremely preterm and very preterm: Biological and social Influences. Child Dev. 2008, 79, 1444-1462. [CrossRef]

41. Wolke, D.; Strauss, V.; Johnson, S.; Gilmore, C.; Marlow, N.; Jaekel, J. Universal gestational age effects on cognitive and basic mathematic processing: 2 cohorts in 2 countries. J. Pediatr. 2015, 166, 1410-1416.e2. [CrossRef] [PubMed]

42. Bauer, A. Ein Verfahren zur Messung des Fuer das Bildungsverhalten Relevanten Sozial Status BRSS Ueberarbeitete Fassung; Deutsches Institut fuer Internationale Paedagogische Forschung: Frankfurt, Germany, 1988.

43. Breeman, L.D.; Jaekel, J.; Baumann, N.; Bartmann, P.; Wolke, D. Neonatal predictors of cognitive ability in adults born very preterm: A prospective cohort study. Dev. Med. Child Neurol. 2017, 59, 477-483. [CrossRef] [PubMed]

44. Wolke, D.; Schmid, G.; Schreier, A.; Meyer, R. Crying and feeding problems in infancy and cognitive outcome in preschool children born at risk: A prospective population study. J. Dev. Behav. Pediatr. 2009, 30, 226-238. [CrossRef] [PubMed]

45. Natsuaki, M.N.; Leve, L.D.; Neiderhiser, J.M.; Shaw, D.S.; Scaramella, L.V.; Ge, X.; Reiss, D. Intergenerational transmission of risk for social inhibition: The interplay between parental responsiveness and genetic influences. Dev. Psychopath. 2013, 25, 261-274. [CrossRef] [PubMed]

46. Pyhälä, R.; Wolford, E.; Kautiainen, H.; Andersson, S.; Bartmann, P.; Baumann, N.; Brubakk, A.-M.; Evensen, K.A.I.; Hovi, P.; Kajantie, E.; et al. Self-reported mental health problems among adults born preterm: A meta-analysis. Pediatrics 2017, 139, e20162690. [CrossRef] [PubMed]

47. Cosentino-Rocha, L.; Klein, V.C.; Linhares, M.B.M. Effects of preterm birth and gender on temperament and behavior in children. Infant Behav. Dev. 2014, 37, 446-456. [CrossRef] [PubMed]

48. Wolke, D.; Lereya, S.T. Long-term effects of bullying. Arch. Dis. Child. 2015, 100, 879-885. [CrossRef] [PubMed]

49. Potijk, M.R.; de Winter, A.F.; Bos, A.F.; Kerstjens, J.M.; Reijneveld, S.A. Higher rates of behavioural and emotional problems at preschool age in children born moderately preterm. Arch. Dis. Child 2012, 97, 112-117. [CrossRef] [PubMed]

50. Nadeau, L.; Tessier, R. Social adjustment at school: Are children with cerebral palsy perceived more negatively by their peers than other at-risk children? Disabil. Rehabil. 2009, 31, 302-308. [CrossRef]

51. Montagna, A.; Nosarti, C. Socio-emotional development following very preterm birth: Pathways to psychopathology. Front. Psychol. 2016, 7, 80. [CrossRef]

52. Healy, E.; Reichenberg, A.; Nam, K.W.; Allin, M.P.G.; Walshe, M.; Rifkin, L.; Murray, R.M.; Nosarti, C. Preterm birth and adolescent social functioning-alterations in emotion-processing brain areas. J. Pediatr. 2013, 163, 1596-1604. [CrossRef] [PubMed]

53. Tucker, D.M.; Derryberry, D.; Luu, P.; Phan, K.L. Anatomy and physiology of human emotion: Vertical integration of brainstem, limbic, and cortical systems. Neuropsychol. Emot. 2000, 56-79.

54. Feldman, R. From biological rhythms to social rhythms: Physiological precursors of mother-infant synchrony. Dev. Psychol. 2006, 42, 175-188. [CrossRef] [PubMed]

55. Levitt, P. Structural and functional maturation of the developing primate brain. J. Pediatr. 2003, 143, 35-45. [CrossRef]

56. Porges, S.W. The polyvagal theory: Phylogenetic contributions to social behavior. Physiol. Behav. 2003, 79, 503-513. [CrossRef]

57. Geva, R.; Feldman, R. A neurobiological model for the effects of early brainstem functioning on the development of behavior and emotion regulation in infants: Implications for prenatal and perinatal risk. J. Child Psychol. Psychiatry 2008, 49, 1031-1041. [CrossRef] [PubMed]

58. Blakemore, S.-J. The social brain in adolescence. Nat. Rev. Neurosci. 2008, 9, 267-277. [CrossRef] [PubMed]

59. Hack, M.; Taylor, H.G. Perinatal brain injury in preterm infants and later neurobehavioral function. JAMA 2000, 284, 1973-1974. [CrossRef] [PubMed]

60. Field, T.M. Visual and cardiac responses to animate and inanimate faces by young term and preterm infants. Child Dev. 1979, 50, 188-194. [CrossRef]

61. Barratt, M.S.; Roach, M.A.; Leavitt, L.A. Early channels of mother-infant communication: Preterm and term infants. J Child Psychol. Psychiatry 1992, 33, 1193-1204. [CrossRef] 
62. De Schuymer, L.; De Groote, I.; Desoete, A.; Roeyers, H. Gaze aversion during social interaction in preterm infants: A function of attention skills? Infant Behav. Dev. 2012, 35, 129-139. [CrossRef] [PubMed]

63. Harel, H.; Gordon, I.; Geva, R.; Feldman, R. Gaze behaviors of preterm and full-term infants in nonsocial and social contexts of increasing dynamics: Visual recognition, attention regulation, and gaze synchrony. Infancy 2011, 16, 69-90. [CrossRef]

64. Feldman, R.; Eidelman, A.I. Neonatal state organization, neuromaturation, mother-infant interaction, and cognitive development in small-for-gestational-age premature infants. Pediatrics 2006, 118, e869-e878. [CrossRef] [PubMed]

65. Nosarti, C.; Nam, K.W.; Walshe, M.; Murray, R.M.; Cuddy, M.; Rifkin, L.; Allin, M.P.G. Preterm birth and structural brain alterations in early adulthood. Neuroimage Clin. 2014, 6, 180-191. [CrossRef] [PubMed]

66. Spittle, A.J.; Treyvaud, K.; Doyle, L.W.; Roberts, G.; Lee, K.J.; Inder, T.E.; Cheong, J.L.Y.; Hunt, R.W.; Newnham, C.A.; Anderson, P.J. Early emergence of behavior and social-emotional problems in very preterm infants. J. Am. Acad. Child Adoles. Psychiatry 2009, 48, 909-918. [CrossRef] [PubMed]

67. Dollar, J.M.; Stifter, C.A.; Buss, K.A. Exuberant and inhibited children: Person-centered profiles and links to social adjustment. Dev. Psychol. 2017, 53, 1222-1229. [CrossRef] [PubMed]

68. Stifter, C.A.; Putnam, S.; Jahromi, L. Exuberant and inhibited toddlers: Stability of temperament and risk for problem behavior. Dev. Psychopathol. 2008, 20, 401-421. [CrossRef]

69. Hirshfeld-Becker, D.R.; Biederman, J.; Calltharp, S.; Rosenbaum, E.D.; Faraone, S.V.; Rosenbaum, J.F. Behavioral inhibition and disinhibition as hypothesized precursors to psychopathology: Implications for pediatric bipolar disorder. Biol. Psychiatry 2003, 53, 985-999. [CrossRef]

70. Derryberry, D.; Rothbart, M.K. Reactive and effortful processes in the organization of temperament. Dev. Psychopath. 1997, 9, 633-652. [CrossRef]

71. Cloninger, C.R. A unified biosocial theory of personality and its role in the development of anxiety states. Psychiatr. Dev. 1986, 3, 167-226.

72. Mathewson, K.J.; Chow, C.H.T.; Dobson, K.G.; Pope, E.I.; Schmidt, L.A.; Van Lieshout, R.J. Mental health of extremely low birth weight survivors: A systematic review and meta-analysis. Psychol. Bull. 2017, 143, 347-383. [CrossRef] [PubMed]

73. Eryigit-Madzwamuse, S.; Strauss, V.; Baumann, N.; Bartmann, P.; Wolke, D. Personality of adults who were born very preterm. Arch. Dis. Child.-Fetal Neonatal Ed. 2015, 100, F524-F529. [CrossRef] [PubMed]

74. Sonuga-Barke, E.J.S.; Kennedy, M.; Kumsta, R.; Knights, N.; Golm, D.; Rutter, M.; Maughan, B.; Schlotz, W.; Kreppner, J. Child-to-adult neurodevelopmental and mental health trajectories after early life deprivation: The young adult follow-up of the longitudinal English and Romanian Adoptees study. Lancet 2017, 389, 1539-1548. [CrossRef]

75. Bruce, J.; Tarullo, A.R.; Gunnar, M.R. Disinhibited social behavior among internationally adopted children. Dev. Psychopath. 2009, 21, 157-171. [CrossRef] [PubMed]

76. Jaekel, J.; Eryigit-Madzwamuse, S.; Wolke, D. Preterm toddlers' inhibitory control abilities predict attention regulation and academic achievement at age 8 years. J. Pediatr. 2016, 169, 87-92. [CrossRef] [PubMed]

77. Bilgin, A.; Wolke, D. Regulatory problems in very preterm and full-term infants over the first 18 months. J. Dev. Behav. Pediatr. 2016, 37, 298-305. [CrossRef] [PubMed]

78. Degnan, K.A.; Hane, A.A.; Henderson, H.A.; Moas, O.L.; Reeb-Sutherland, B.C.; Fox, N.A. Longitudinal stability of temperamental exuberance and social-emotional outcomes in early childhood. Dev. Psychol. 2011, 47, 765-780. [CrossRef] [PubMed]

79. Wolke, D.; Eryigit-Madzwamuse, S.; Gutbrod, T. Very preterm/very low birthweight infants' attachment: Infant and maternal characteristics. Arch. Dis. Child.-Fetal Neonatal Ed. 2014, 99, F70-F75. [CrossRef]

80. Bilgin, A.; Wolke, D. Maternal Sensitivity in Parenting Preterm Children: A Meta-analysis. Pediatrics 2015, 136, e177-e193. [CrossRef]

81. Feldman, R.; Eidelman, A.I. Maternal postpartum behavior and the emergence of infant-mother and infant-father synchrony in preterm and full-term infants: The role of neonatal vagal tone. Dev. Psychobiol. 2007, 49, 290-302. [CrossRef]

82. Wijnroks, L. Maternal recollected anxiety and mother-infant interaction in preterm infants. Infant Ment. Health J. 1999, 20, 393-409. [CrossRef]

83. Muller-Nix, C.; Forcada-Guex, M.; Pierrehumbert, B.; Jaunin, L.; Borghini, A.; Ansermet, F. Prematurity, maternal stress and mother-child interactions. Early Hum. Dev. 2004, 79, 145-158. [CrossRef] [PubMed] 
84. Grunau, R.E. Neonatal pain in very preterm infants: Long-term effects on brain, neurodevelopment and pain reactivity. Rambam Maimonides Med. J. 2013, 4, e0025. [PubMed]

85. Newnham, C.A.; Milgrom, J.; Skouteris, H. Effectiveness of a modified mother-infant transaction program on outcomes for preterm infants from 3 to 24 months of age. Infant Behav. Dev. 2009, 32, 17-26. [CrossRef]

86. Guilherme Monte Cassiano, R.; Gaspardo, C.M.; Cordaro Bucker Furini, G.; Martinez, F.E.; Martins Linhares, M.B. Impact of neonatal risk and temperament on behavioral problems in toddlers born preterm. Early Hum. Dev. 2016, 103, 175-181. [CrossRef]

87. Klein, V.C.; Gaspardo, C.M.; Martinez, F.E.; Martins Linhares, M.B. Neonatal characteristics and temperament predict behavior problems in children born preterm. J. Hum. Growth Dev. 2015, 25, 331-340. [CrossRef]

88. Perricone, G.; Morales, M.R. The temperament of preterm infant in preschool age. Ital. J. Pediatr. 2011, $37,4$. [CrossRef]

89. Moore, T.; Hennessy, E.M.; Myles, J.; Johnson, S.J.; Draper, E.S.; Costeloe, K.L.; Marlow, N. Neurological and developmental outcome in extremely preterm children born in England in 1995 and 2006: The EPICure studies. BMJ Br. Med. J. 2012, 345, e7961. [CrossRef]

90. Pierrat, V.; Marchand-Martin, L.; Arnaud, C.; Kaminski, M.; Resche-Rigon, M.; Lebeaux, C.; Bodeau-Livinec, F.; Morgan, A.S.; Goffinet, F.; Marret, S.; et al. Neurodevelopmental outcome at 2 years for preterm children born at 22 to 34 weeks' gestation in France in 2011: EPIPAGE-2 cohort study. Br. Med. J. 2017, 358, j3448. [CrossRef]

91. Cheong, J.L.Y.; Anderson, P.J.; Burnett, A.C.; Roberts, G.; Davis, N.; Hickey, L.; Carse, E.; Doyle, L.W.; Victorian Infant Collaborative Study, G. Changing neurodevelopment at 8 years in children born extremely preterm since the 1990s. Pediatrics 2017, 139, e20164086. [CrossRef]

92. Twilhaar, E.S.; de Kieviet, J.F.; Aarnoudse-Moens, C.S.H.; van Elburg, R.M.; Oosterlaan, J. Academic performance of children born preterm: A meta-analysis and meta-regression. Arch. Dis. Child.-Fetal Neonatal Ed. 2017, 103, F322-F330. [CrossRef] [PubMed]

93. Komsi, N.; Räikkönen, K.; Pesonen, A.-K.; Heinonen, K.; Keskivaara, P.; Järvenpää, A.-L.; Strandberg, T.E. Continuity of temperament from infancy to middle childhood. Infant Behav. Dev. 2006, 29, 494-508. [CrossRef] [PubMed]

94. Doyle, L.; Anderson, P.; Battin, M.; Bowen, J.; Brown, N.; Callanan, C.; Campbell, C.; Chandler, S.; Cheong, J.; Darlow, B.; et al. Long term follow up of high risk children: Who, why and how? BMC Pediatr. 2014, 14. [CrossRef] [PubMed]

95. Webster-Stratton, C.; Reid, M.J. Treating conduct problems and strengthening social and emotional competence in young children: The Dina Dinosaur treatment program. J. Emot. Behav. Disord. 2003, 11, 130-143. [CrossRef]

96. Suarez, G.L.; Morales, S.; Metcalf, K.; Pérez-Edgar, K.E. Perinatal complications are associated with social anxiety: Indirect effects through temperament. Infant Child Dev. 2019, 28, e2130. [CrossRef]

97. Miranda, L.; Jaekel, J.; Heuser, K.M.; Wolke, D. Developmental cascades of social inhibition and friendships in preterm and full-term children. Presented at the Society for Research in Child Development (SRCD) Biennial Meeting, Baltimore, MD, USA, 22 March 2010.

(C) 2019 by the authors. Licensee MDPI, Basel, Switzerland. This article is an open access article distributed under the terms and conditions of the Creative Commons Attribution (CC BY) license (http://creativecommons.org/licenses/by/4.0/). 